\title{
Editorial: International Perspectives on Health and Safety among Dairy Workers: Challenges, Solutions and the Future
}

\author{
Martina Carola Jakob ${ }^{1 *}$ and John Rosecrance ${ }^{2}$ \\ ${ }^{1}$ Leibniz Institute for Agricultural Engineering Potsdam-Bornim (LG), Potsdam, Germany, ${ }^{2}$ College of Veterinary Medicine and \\ Biomedical Sciences, Colorado State University, Fort Collins, CO, United States
}

Keywords: dairy, milking parlor, workload assessment, parlor worker, risk control

Editorial on the Research Topic

International Perspectives on Health and Safety among Dairy Workers: Challenges, Solutions and the Future

OPEN ACCESS

Edited by:

How-Ran Guo,

National Cheng Kung University,

Taiwan

Reviewed by:

Timothy Lynn Taylor,

Retired, Wellton, Arizona,

United States

Jean O'Dwyer,

University of Limerick, Ireland

*Correspondence:

Martina Carola Jakob mjakob@atb-potsdam.de

Specialty section: This article was submitted to Occupational Health and Safety, a section of the journal

Frontiers in Public Health

Received: 29 May 2017

Accepted: 23 October 2017 Published: 17 November 2017

Citation: Jakob MC and Rosecrance J (2017) Editorial: International Perspectives on Health and Safety among Dairy Workers: Challenges, Solutions and the Future.

Front. Public Health 5:294. doi: 10.3389/fpubh.2017.00294
The purpose of this special topics edition of Frontiers in Public Health was to present an international perspective on current occupational health research related to workers in the dairy industry. The 32 contributing authors were occupational health researchers from eight countries, including Argentina, Finland, Ireland, Italy, Spain, Sweden, Uganda, and the United States. The majority of authors were part of the International Dairy Research Consortium, a group of international dairy researchers focused on improving the health and safety of dairy workers throughout the world. In the first year of publication, there were approximately 16,000 views and 1,800 article downloads of the 10 published papers.

Milking cows is one of the major work tasks on dairy farms regardless of herd size. The occupational risks associated with milking cows are just as significant for the Latino worker (Menger et al.; Menger et al.) in a large herd American dairy as they are for the Ugandan farmer (Lunner-Kolstrup and Ssali) with five dairy cows. The perception of milk production by consumers in developed countries is an industry that is primarily automated. Although milking tasks have changed in modern milking parlors, parlor workers still experience work-related aches and pain and have more accidents compared to other professions (Pinzke). In this issue, researchers present comprehensive workload analyses and reported that preparing the udder and attaching the milking cluster is associated with awkward postures and high muscular loads of the upper-limb among dairy workers (Mixco et al.; Masci et al.). Other than robotic milking (Karttunen et al.), there are few mechanical interventions that completely eliminate the physical work exposures that are associated with musculoskeletal disorders among dairy parlor workers. Occupational challenges, such as awkward working postures, repetitive tasks, long or unfavorable working hours, cold or hot and wet working environments, significant time pressures, and high workloads do little to attract the next generation to take up this profession.

There has been a worldwide trend of increasing farm size with a simultaneous reduction in the number of farms (Pinzke). Increasing farm size requires hiring more workers, often in regions where the only labor source available are immigrant laborers. Additionally, farm owners need to learn how to manage and train a very diverse workforce in farm operations, including health and safety. Among the published articles, four address the issue regarding health and safety and worker training. Menger et al. and Menger et al. state in their conclusions that the management has a large impact on worker perception of health and safety. Managements' leadership skills are of major importance. 
Clear communication of tasks, addressing health and safety, providing adequate tools, or giving feedback reduces frustration and increases job satisfaction. Rovai et al. present the development of a unique series of short weekly toolbox talks to train immigrant dairy workers on issues related to animal care, cow comfort, and personal safety. The outcomes resulting from the dairy toolbox talks included increased knowledge, greater safety awareness, and enhanced job satisfaction for the workers. Finally, Menger et al. and Menger et al. suggest that the development of dairy training programs emphasize and consider the cultural uniqueness of the target population. Cultural specification of training is a significant issue as the majority of dairy workers in developed countries are immigrants. This issue is also emphasized by Lunner-Kolstrup and Ssali who investigated a very different situation of small-scale dairy farmers in Uganda. Additionally, Furey et al. addressed the role of financial threats on the mental wellbeing of dairy farmers. This is an important issue because of increasing farm sizes and new, highly sophisticated technologies that require significant resources, while both are occurring in an economy of volatile milk prices.

Although requiring significant financial investment, one of the most effective measures of reducing the workload on a dairy farm is investing in automatic milking systems (milking robots).

Conflict of Interest Statement: The authors declare that the research was conducted in the absence of any commercial or financial relationships that could be construed as a potential conflict of interest.

Copyright (c) 2017 Jakob and Rosecrance. This is an open-access article distributed under the terms of the Creative Commons Attribution License (CC BY).
Karttunen et al. describe the health and safety situation of Finnish farms with milking robots. A robot can reduce labor and musculoskeletal risk, but also creates new stresses and challenges for the farmer. Finally, Manbeck et al. discuss the dangers of on-farm manure storage pits that contain both toxic and asphyxiating gases such as hydrogen sulfide, carbon dioxide, methane, and ammonia. The authors present online design aids to evaluate manure pit ventilation systems that would reduce entry risk.

\section{AUTHOR CONTRIBUTIONS}

Both authors contributed equally.

\section{FUNDING}

This publication was partially supported by the Mountain and Plains Education and Research Center, Grant T42OH009229 and by the High Plains Intermountain Center for Agricultural Health and Safety, Grant U54 OH008085, both funded by the Centers for Disease Control and Prevention. Its contents are solely the responsibility of the authors and do not necessarily represent the official views of the Centers for Disease Control and Prevention or the Department of Health and Human Services.

The use, distribution or reproduction in other forums is permitted, provided the original author(s) or licensor are credited and that the original publication in this journal is cited, in accordance with accepted academic practice. No use, distribution or reproduction is permitted which does not comply with these terms. 